\title{
Effect of metiamide on the response to secretin and cholecystokinin in man
}

\author{
B. THJODLEIFSSON AND K. G. WORMSLEY ${ }^{1}$
}

From the Department of Therapeutics, University of Dundee

SUMMARY The effects of intravenous metiamide on the pancreatic exocrine response to intravenous infusion of secretin plus cholecystokinin has been studied in eight patients with duodenal ulceration. The secretion of bicarbonate and water was not altered by metiamide. The secretion of enzymes was significantly less than control during infusion of metiamide. The differences between the pancreatic and gastric responses to metiamide are discussed.

Recent studies have indicated that metiamide exerts a powerful inhibitory effect on nocturnal, basal, and stimulated gastric secretion of acid and pepsin in patients with duodenal ulcer and it has therefore been suggested that metiamide may prove useful in the treatment of duodenal ulceration and related conditions (Carter, Werner, Forrest, Heading, Park, and Shearman, 1974; Milton-Thompson, Jenkins, Williams, and Misiewicz, 1974; Thjodleifsson and Wormsley, 1974). In view of these powerful inhibitory effects on gastric secretion, it seemed pertinent to examine the effects of metiamide on pancreatic exocrine secretion. The present study was therefore undertaken in order to investigate the effect of metiamide on the pancreatic and gastric responses to secretin and cholecystokinin (CCK) in patients with duodenal ulceration.

\section{Materials and Methods}

Eight patients with duodenal ulceration, proven endoscopically, each had two tests in random order and separated by more than seven days, after full explanation and consent. After an overnight fast, the stomach and duodenum were intubated, as described previously (Shepherd, Stewart, Thjodleifsson, and Wormsley, 1974). During each test, the patients received a continuous intravenous infusion of secretin ${ }^{2}$ ( 1 clinical unit $/ \mathrm{kg}$ body weight-hour) plus $\mathrm{CCK}^{2}$ (1 Ivy unit/kg-hour) in

${ }^{1}$ Please address communications to: KGW, Ninewells Hospital, Dundee DD2 1 UB.

${ }^{2}$ The secretin and CCK were obtained from the G.I.H. Laboratory, Karolinska Institute, Stockholm, Sweden.

Received for publication 11 September 1974.
$0 \cdot 15 \mathrm{M}$ sodium chloride. The hormones were either administered alone, in the control test, or together with metiamide. The metiamide was given in two schedules.

1 Five patients received a continuous intravenous infusion of $200 \mathrm{mg} /$ hour for one hour. The infusion of metiamide started at the same time as the infusion of secretin and CCK.

2 Three patients received a continuous intravenous infusion of $100 \mathrm{mg} /$ hour of metiamide and, in addition, were given a loading dose of $75 \mathrm{mg}$ metiamide 20 minutes before the start of the infusion of metiamide and hormones. This dose combination of metiamide results in a constant blood level of metiamide during the course of the test (to be published).

Each patient received a continuous infusion of polyethylene glycol (PEG) $4000(2.5 \mathrm{~g} / 1$ in $0.15 \mathrm{M}$ sodium chloride) into the duodenal bulb throughout the test, in order to monitor the completeness of duodenal aspiration.

The gastric and duodenal contents were aspirated continuously and separately in 15-minute batches. The concentration of acid was measured by titrating with $0 \cdot 1 \mathrm{M}$ sodium hydroxide to $\mathrm{pH} 7$. Bicarbonate was measured by adding a known excess of acid, boiling, and backtitrating the residual acid. Tryptic activity was measured titrimetrically, using p-tosylarginine methyl ester as substrate. The bile pigment concentration was expressed as the icteric index. Peptic activity was measured by the method of Hunt (1948). Polyethylene glycol was measured by the method of Hyden (1955).

The paired responses from individual subjects were compared by means of the $t$ test. 

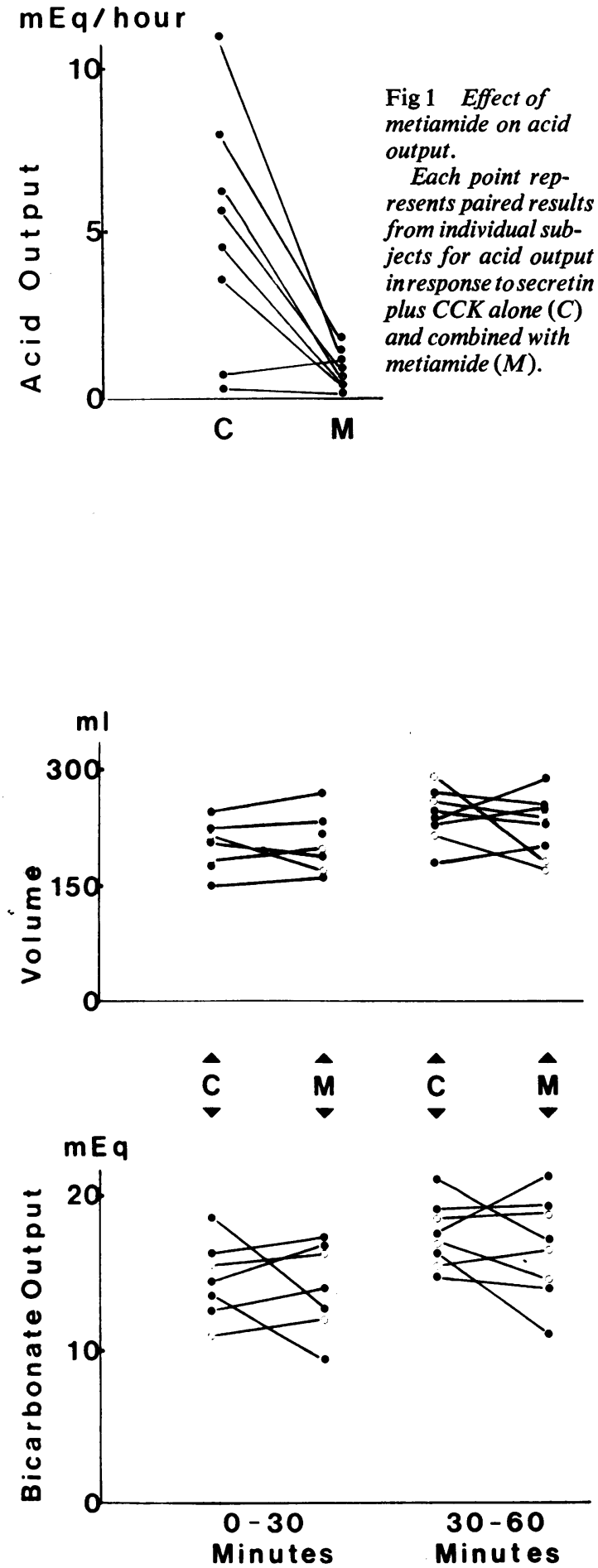

Fig 2 Effect of metiamide on rate of secretion into duodenum and output of bicarbonate.
Figs 2 and 3 Each pair of results, symbolised by joined circles, represents the volume of duodenal aspirate in response to secretin plus CCK alone (columns C) or combined with metiamide (columns $M$ ).

The two sets of results refer to the first 30 minutes of infusion of secretin plus CCK (0-30 minutes) and to the remaining 30 minutes of the test (30-60 minutes).

The open circles represent results from three individuals who received the loading dose of metiamide in addition to the continuous intravenous infusion of the drug. The 0-30 minute response from one of these individuals is not depicted, because the samples were spoiled.

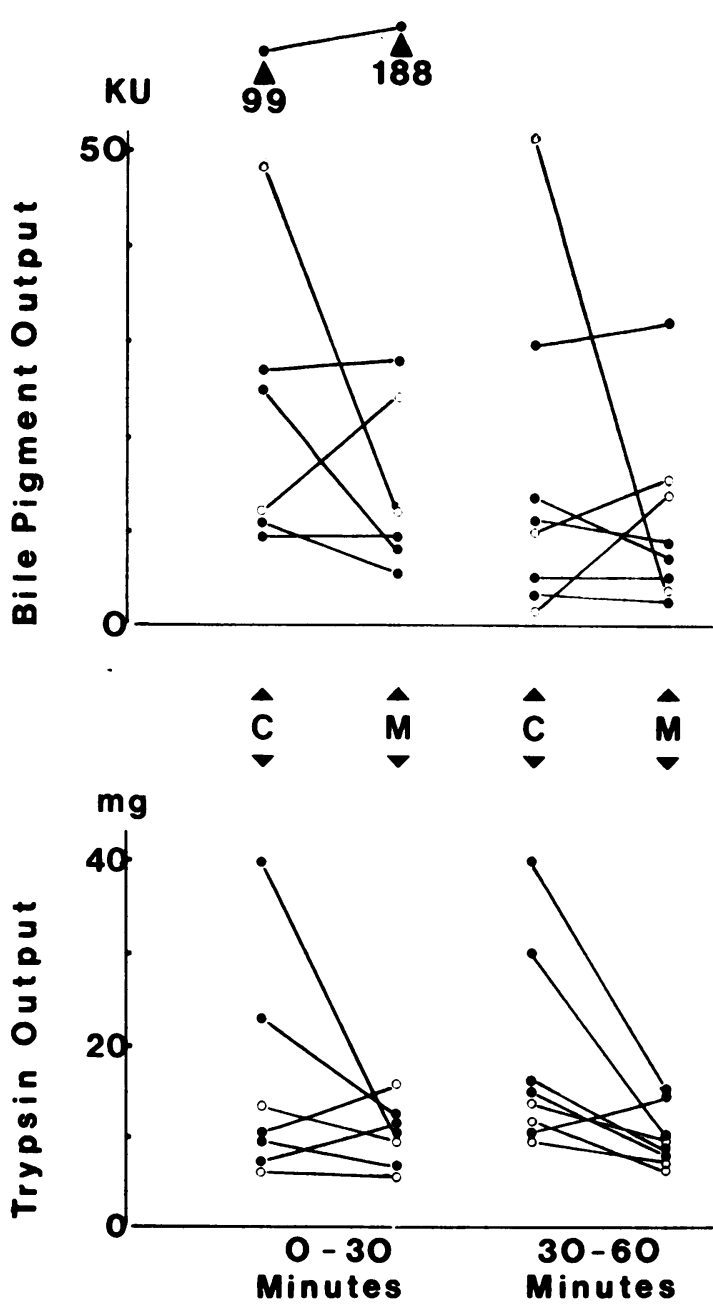

Fig 3 Effect of metiamide on outputs of trypsin and bile pigment. 


\section{Results}

The average recovery of PEG was $94 \%$.

The effects of the two metiamide schedules on pancreatic secretion and on cholecystokinesis did not differ significantly and the results were therefore pooled for the purpose of analysis and discussion.

Metiamide virtually abolished the gastric secretion of acid in response to the small intestinal hormones (fig 1).

Metiamide had no significant effect on the secretion of bicarbonate nor on the rate of secretion of fluid into the duodenum in response to secretin plus CCK (fig 2).

Trypsin secretion in response to secretin plus CCK decreased significantly $(\mathrm{P}<0.05)$ only during the second 30-minute period of the test (fig 3).

Metiamide had no consistent effect on the cholecystokinetic response to the combined infusion of the small intestinal hormones (fig 3).

\section{Discussion}

Despite the profound inhibition of the gastric secretion of acid and pepsin in patients with duodenal ulcer, both in response to pentagastrin (Thjodleifsson and Wormsley, 1974), and, as shown in the present study, in response to a combination of secretin plus CCK, metiamide exerts only minimal inhibitory effects on exogenously stimulated pancreatic secretion and cholecystokinesis in man. Specifically, the administration of metiamide was not associated with significant change in the pancreatic secretion of electrolytes and water and did not affect the initial discharge of zymogens from the pancreas. The only effect which reached a level of statistical significance was the inhibition of the enzyme-secretory response to sustained stimulation with exogenous secretin plus cholecystokinin.

The cause of the very marked differences between the effects of metiamide on gastric and on pancreatic secretion is not clear. Exogenous secretagogues, such as pentagastrin, do not have any significant stimulant effect on the human exocrine pancreas (Wormsley, Mahoney, and Ng, 1966; Petersen, Berstad, and Myren, 1971) although pentagrastrin is a strong stimulant of human gastric secretion. If the secretory response to exogenous stimulants depends on interaction between stimulant and receptors and if metiamide acts by competing with gastrin (or histamine) receptors, then minimal pancreatic inhibitory effects would indeed be expected. Alternatively, the absence of an inhibitory effect of metiamide on pancreatic secretion would be expected if histamine were involved in the mediation of gastric secretory stimulation by exogenous stimulants (such as pentagastrin) but were not involved in mediating the effect of secretin and CCK on the pancreas.

$\mathrm{KGW}$ is in receipt of a grant from the Scottish Hospital Endowments Research Trust. Themetiamide was kindly supplied by Dr M. Bloch, Smith, Kline \& French Laboratories, Ltd, Welwyn Garden City. The technical assistance of Mrs F. Dear and Miss S. Drummond is gratefully acknowledged.

References

Carter, D. C., Werner, M., Forrest, J. H., Heading, R. C., Park, J., and Shearman, D. J. C. (1974). The effect of histamine $\left(\mathrm{H}_{2}-\right)$ receptor blockade on vagally-induced gastric secretion in man. Scot. med.J., 19, 153.

Hunt, J. N. (1948). A method for estimating peptic activity in gastric contents. Biochem. J., 42, 104-109.

Hydén, S. (1956). A turbidometric method for the determination of higher polyethylene glycols in biological materials. K. LantbrHögsk. Annlr., 22, 139-145.

Milton-Thompson, G. J., Jenkins, D. J. A., Williams, J. G., and Misiewicz, J. J. (1974). Inhibition of nocturnal acid secretion in duodenal ulcer by one oral dose of metiamide. Lancet, 1 , 693-694.

Petersen, H., Berstad, A., and Myren, J. (1971). Effect of pentagastrin on pancreatic secretion in man. In Gastrointestinal Hormones and Other Subjects, edited by E. H. Thaysen, pp. 72-76. Munksgaard, Copenhagen.

Shepherd, A. M. M., Stewart, W. K., Thjodleifsson, B., and Wormsley, K. G. (1974). Further studies of gastric hypersecretion in chronic renal failure. Brit. med. J., 1, 96-98.

Thjodleifsson, B., and Wormsley, K. G. (1974). Gastric response to metiamide. Brit. med. J., 2, 304-306.

Wormsley, K. G., Mahoney, M. P., and Ng, M. (1966). Effects of a gastrin-like pentapeptide (I.C.I. 50,123) on stomach and pancreas. Lancet, 1, 993-996. 